University of Rhode Island

DigitalCommons@URI

1984

\title{
The effects of high pressure and high temperature on some physical properties of ocean sediments
}

Roger Morin

University of Rhode Island

Armand J. Silva

University of Rhode Island

Follow this and additional works at: https://digitalcommons.uri.edu/oce_facpubs

Terms of Use

All rights reserved under copyright.

\section{Citation/Publisher Attribution}

Morin, R., \& Silva, A. J. (1984). The effects of high pressure and high temperature on some physical

properties of ocean sediments. Journal of Geophysical Research, 89(B1), 511-526. doi: 10.1029/ JB089iB01p00511

Available at: http://dx.doi.org/10.1029/JB089iB01p00511

This Article is brought to you for free and open access by the Ocean Engineering at DigitalCommons@URI. It has been accepted for inclusion in Ocean Engineering Faculty Publications by an authorized administrator of DigitalCommons@URI.For more information, please contact digitalcommons-group@uri.edu. 
JOURNAL OF GEOPHYSICAL RESEARCH, VOL. 89, NO. B1, PAGES 511-526, JANUARY 10, 1984

THE EFFECTS OF HIGH PRESSURE AND HIGH TEMPERATURE

ON SOME PHYSICAL PROPERTIES OF OCEAN SEDIMENTS

Roger Morinl and Armand J. Silva

Department of Ocean Engineering, University of Rhode Island

Abstract. A series of laboratory experiments was conducted with four ocean sediments, two biogenic oozes and two clays. Permeability and thermal conductivity were directly measured as a function of porosity, and the testing program was designed to identify any dependence of these physical properties upon hydrostatic pressure and temperature. The results show no discernible effects of pressure, within the range of 2-60 MPa, upon the permeability of any of the samples. Temperature effects, from 220 to $220{ }^{\circ} \mathrm{C}$, upon this property are accounted for by applying a viscosity correction to the permeating seawater. Previous investigations have suggested the existence of a pressure-induced and/or a temperature-induced breakdown of the absorbed water which surrounds clay particles, thereby promoting an increase in sediment permeability. our experimental findings cannot confirm this phenomenon and fail to provide a satisfactory solution to the conflicting data which now exist between the pore water velocities inferred from nonlinear thermal profiles of ocean sediments and those fluid velocities derived from Darcy's law and laboratory permeability data. The effects of sizeable variations in pressure and temperature upon sediment thermal conductivity are found to reflect closely the behavior of the conductivity of the liquid phase alone under these same changes in environmental conditions. This is not surprising due to the relatively narrow range of high porosities encountered in this study. Empirical equations are developed which allow sediment thermal conductivity to be calculated as a function of temperature and void ratio. A hydrostatic pressure correction term is also presented.

\section{Introduction}

Thermal models have been developed which predict the subsidence and thermal decay of the lithosphere with distance away from spreading centers. In areas of thick and uniform sediment cover, conductive heat flow measurements have generally been in agreement with the predicted values. Other areas, however, have produced anomalously low and variable heat flow data [Williams et al., 1974; Davis and Lister, 1977]. These have usually been regions of thin sediment cover and/or basement outcrops and have led investigators to hypothesize that hydrothermal convection through the ocean floor is a prominent

INow at the Department of Earth and Planetary Sciences, Massachusetts Institute of Technology.

Copyright 1984 by the American Geophysical Union.

Paper number 3B1212.

0148-0227/84/003B-1212\$05.00 mechanism for heat loss near active spreading ridges.

The concept of hydrothermal activity through a sediment column has been reinforced by the existence of nonlinear thermal profiles [Anderson et al., 1979; Langseth and Herman, 1981]. These nonlinear gradients are usually concave down and infer upward fluid flow through the sediment cover driven by excess pore pressures. The fluid velocities derived from these pressure gradients can be quite large, with the implied forces often approaching or exceeding the lithostatic load. sediment samples obtained near regions of suspected water movement have not been substantially underconsolidated, and the large values of volume flux estinated from the geothermal data have been difficult to support.

Langseth [1980] and Abbott et al. [1981] have offered a possible explanation for this discrepancy by suggesting that sediment permeabilities at in situ conditions may differ from conventional laboratory test results. If large hydrostatic pressures and/or elevated temperatures were to produce physicochemical changes in a sediment fabric, perhaps a significant increase in permeability would result. This larger permeability would, in turn, tend to equalize the values for fluid velocity derived from the geothermal data and from Darcy's law, thereby providing additional support for the concept of convective heat loss. If this physicochemical phenomenon were to exist, it would also have ramifications to the Department of Energy's Subseabed Disposal Program [Anderson et al., 1976], where sediment physical properties must be known at their in situ conditions of large pressures and high temperatures in order to model confidently heat and mass transport near the waste canisters.

with this as a background, a project was undertaken to measure the permeability and the thermal conductivity of various sediment types through wide ranges of hydrostatic pressure and temperature. Most of the early permeability tests on ocean sediments were conducted at atmospheric pressure. Silva et al. [1981] and J. Crowe and A.J. Silva (unpublished manuscript, 1982) have noted the importance of subjecting a laboratory sample to backpressure during testing in order to dissolve any air bubbles which might inhibit fluid flow; these tests, however, have only been performed at hydrostatic pressures of the order of $1 \mathrm{MPa}$. Permeability tests at variable temperatures have only been run over a narrow range, with temperature effects being accounted for by applying a viscosity correction to the pore fluid [Bowles, 1978]. The variation in sediment thermal conductivity with hydrostatic pressure has not been determined, and its dependence upon temperature has only been examined over a $300^{\circ} \mathrm{C}$ range [Ratcliffe, 1960; MacDonald and Simmons, 1972]. 
This paper presents the results of a systematic series of experiments designed to determine the effect of hydrostatic pressure (2-60 MPa) and temperature $\left(220-220^{\circ} \mathrm{C}\right)$ on the permeability and thermal conductivity of four sediment types as a function of void ratio. The void ratio, e, is defined as

$$
\mathrm{e}=\mathrm{v}_{\mathrm{v}} / \mathrm{v}_{\mathrm{s}}
$$

where $v_{v}$ is the volume of volds and $v_{s}$ is the volume of solids (exclusive of the dissolved salts). The results are analyzed from two perspectives: (1) the effect of pressure and temperature on the sediment matrix with its associated adsorbed water, and (2) the effect of pressure and temperature on the pore fluid itself.

\section{Sediment Samples}

Undisturbed samples of two biogentc sediments of interest to this study were obtained from piston cores. The siliceous specimens were retrieved from the Guaymas Basin of the Gulf of California, while the calcareous samples were taken near the Galapagos Spreading Center. Geothermal anomalies have been reported in both of these areas [Lawver et al., 1975; Green et al., 1981]. Undisturbed samples of illitic clay were taken from large-diameter gravity cores retrieved from the north-central Pacific, while the smectite samples are homogenized and reconstituted (remolded) specimens originally obtained from the same general area. The four sediment types are identified in Table 1.

A series of four cylindrical samples, $10 \mathrm{~cm}$ long by $5 \mathrm{~cm}$ in diameter, were obtained along the length of each of the respective cores. The samples from each core were taken in very close proximity to each other in order to minimize compositional variations among them.

Mineralogical analyses of each series of four specimens showed them to be very simtlar, and the test results are examined with mineralogy being considered a constant parameter (see Table 2 ).

\section{Experimental Procedure}

Sediment permeability was measured directly and flow was asumed to be governed by Darcy's law.

$$
\frac{\mathrm{q}}{\mathrm{A}}=\mathrm{ki}
$$

where $q / A$ is the flow rate per unit area $(\mathrm{cm} / \mathrm{s})$, $k$ is the coefficient of permeability $(\mathrm{cm} / \mathrm{s})$, and $i$ is the hydraulic gradient (dimensionless). The permeability, $k$, is a coefficlent of proportionality between the superficial velocity of the permeating fluid and the nondimensional hydraulic gradient. Applying a known pressure gradient across a sample and measuring the corresponding flow rate yields a value for the permeability of the specimen. Silva et al. [1981] and Nickerson [1978] adapted the backpressure consolidometer in order to perform this experiment at low hydrostatic pressures.

Thermal conductivity data were obtained by the standard needle probe method [Jaeger, 1958; Von Herzen and Maxwell, 1959]. This analysis shows that for large times and a small radius, the temperature increase of the probe can be 
approximated by the following relationship:

$$
T=\frac{Q}{4 \pi j} \ln \frac{4 a t}{c r^{2}}
$$

where

$t$ temperature of the needle;

$Q$ heat input per unit length per unit time;

$j$ thermal conductivity of sediment;

$t$ time;

$\alpha$ thermal diffusivity of sediment;

$r$ needle radius;

c constant $=1.781$.

Although the experimental principles described by Silva et al. [1981) and by Von Herzen and Maxwell [1959] were employed In this study, the laboratory hardware had to be extensively modified in order to accommodate the large hydrostatic pressures, high temperatures, and corrosive environment. The test apparatus is described by R. Morin and A.J. Silva (unpublished manuscript, 1982). It has the capacity of axially consolidating a sample, thereby simulating compaction in the sediment column. At any desired void ratio, sediment permeability and thermal conductivity are measured at hydrostatic pressures ranging from 2 to $62 \mathrm{MPa}$ and at temperatures from 220 to $2200 \mathrm{C}$. A schematic of the equipment is shown in Figure 1 . During a permeability test, a small, constant differential pressure is produced across the sample by the two dead-weight testers. This hydraulic gradient initiates water flow, with water moving out of one bellows through the sediment and into the second bellows. These devices are calibrated such that a linear bellows displacement is translated into volume change.

Each series of sediment samples from the four sediment types was tested at 220, 800 , 1500, and 2200 C. An initial experiment, which was performed at room temperature, involved the variable pressure studies. The tests conducted at the higher temperatures were performed at a constant pressure equal to the in situ hydrostatic pressure of the specific sample.

\section{Hydrostatic Pressure Effects}

An ocean sediment is composed of a particle-water-electrolyte system, where farce fields associated with each of these constituents may often interact and affect sediment structure. Where grain size and particle weight are relatively large, gravitational forces dominate behavior, and interparticle forces are correspondingly small. This is the case for the biogenic samples tested in this study, and the grain size data are presented in Table 1. Hydrostatic pressure is not expected to influence the behavior of these two sediment types. It should be noted that carbonates do become soluble in seawater when exposed to hydrostatic pressures greater than those corresponding to a local "carbonate compensation depth" of approximately $4000 \mathrm{~m}$. Carbonate dissolution is therefore a function of pressure. The in situ water depth of the calcareous ooze in this study, however, is above this critical depth, and the variable pressure tests performed at larger pressures were
Table 2. Mineralogical Composition

\begin{tabular}{ll} 
Sample & Composition \\
\hline Siliceous Ooze* & $53.88 \mathrm{SiO}_{2}, 8.28 \mathrm{CaCO}$ \\
Calcareous Ooze* & $65.08 \mathrm{CaCO}_{3}, 20.68 \mathrm{SiO}$ \\
Illite** & 72.98 illite, 18.18 chlorite, \\
& 5.98 kaolinite, 3.18 smectite \\
Smect1te*t & 21.78 smectite, 56.18 1llite, \\
& 2.78 chlorite, 19.18 \\
& kaolinite
\end{tabular}

* Percent of total.

**Percent of clay fraction.

not maintained for a long enough perlod of time to produce dissolution effects.

clay particles have a small size and a large surface area and are greatly influenced by the various force field interactions. The effect of hydrostatic pressure on these phenomena, along with the corresponding effect on physical properties, is not well understood. A clay particle is surrounded by an assemblage of hydrated ions which accumulates near its surface due to electrostatio attraction. The ion concentration diffuses away from the particle surface to a low concentration in the bulk or "free" water. This conditon is analogous to that of gas molecules in the earth's atmosphere, where gravity and diffusion counteract each other. The distribution of ions adjacent to the clay particle is known as the diffuse double layer. The principal theory proposed to describe this distribution and the corresponding forces which it produces is known as the Gouy-Chapman theory. The derivation of this theory is presented in detail by van olphen [1977].

The adsorbed water, or the diffuse double layer, is held to the clay surface and is not considered part of the bulk water. Therefore any change in the thickness of this layer will affect the volume of the free water and the size of the void space. It has been hypothesized that changes in pressure may affect this thickness and, in turn, cause associated changes in sediment permeability. Formulas describing the potential and charge distributions of interacting double layers are presented by verwey and overbeek [1948]. The size of the double layer and the relative distance between particles for the two particular clays of interest are calcuated in the appendix. As can be seen from equation (AI), the extension of the double layer into the solution is a function of a number of parameters.

The effect of pressure variation on $E$, the dielectric constánt, in water has been examined analytically by owen and Brinkley [1943]. Their results are analyzed by Hamann [1957] where $\varepsilon$ is shown to increase by approximately 3.48 due to a pressure increase from 0.1 to $60 \mathrm{MPa}$. Referring to equation ( $A 1)$, it can be seen that this significant increase in pressure can produce a 1.88 increase in the size of the double layer due to the variation in the magnitude of the 


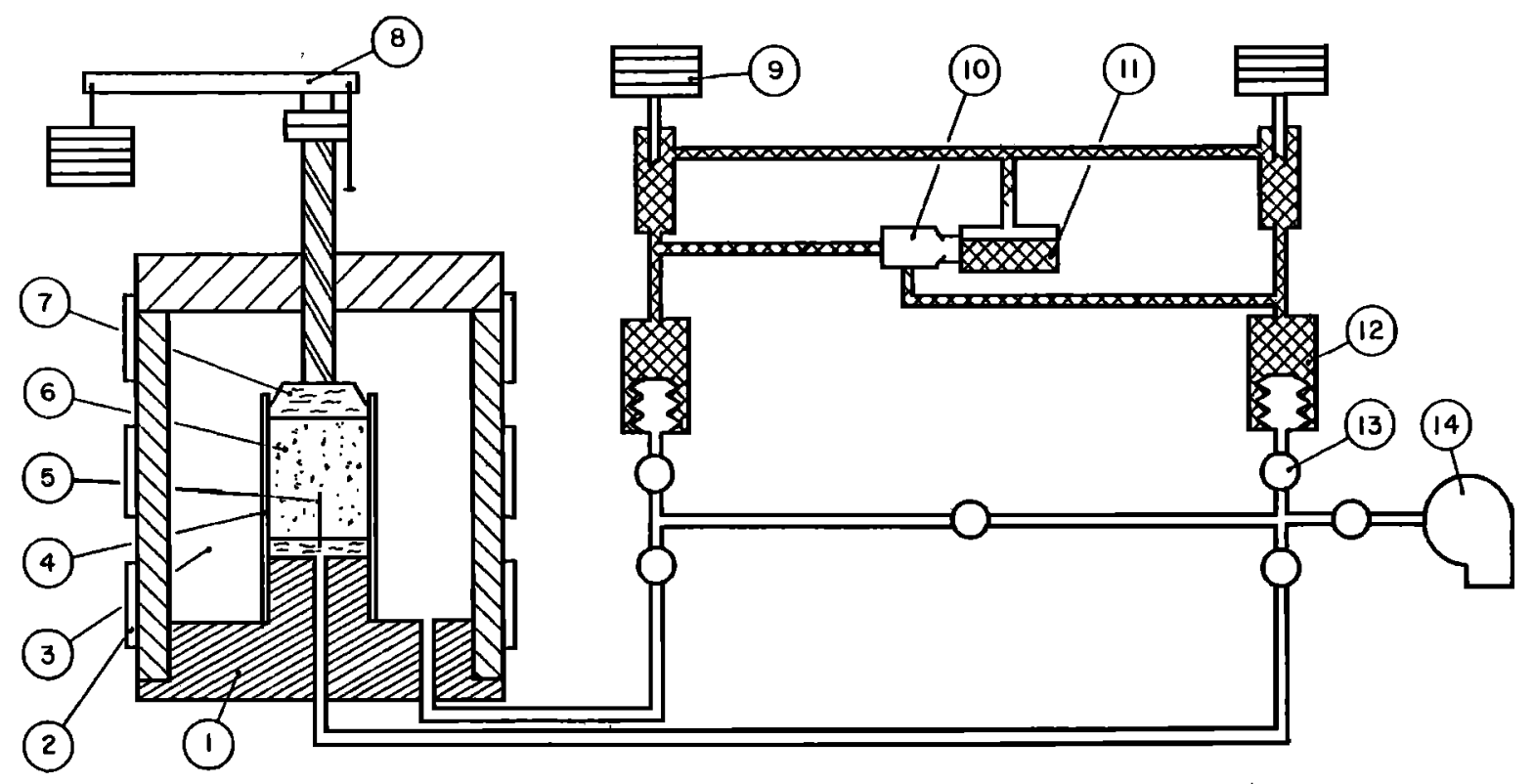

DIAGRAM OF APPARATUS
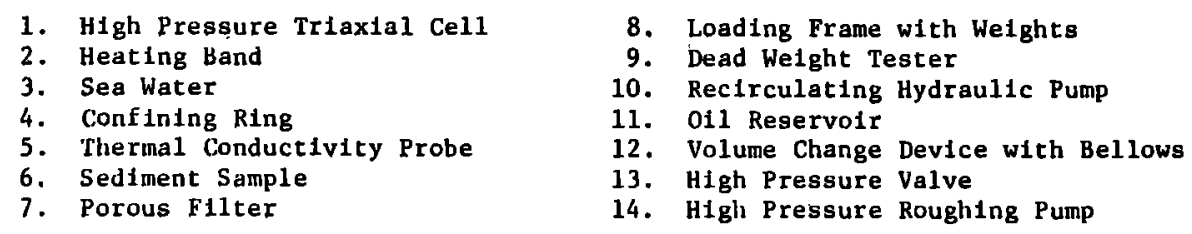

Fig. 1. Schematic diagram of laboratory apparatus.

dielectric constant. On the other hand, seawater is compressible, and an increase in pressure produces an increase in ion concentration. This condition tends to counterbalance the above effect.

Certain shortcomings in the Gouy-Chapman theory have been suggested, and refinements have been proposed [Bolt, 1955]. In the original theory the ions are treated as point charges, with the effect of ion size being neglected. Stern [1924] postulated a more realistic double-layer model by considering this variable. simply stated, the larger the cation size, the more space is required to accommodate enough of them to satisfy the clay particle charge. Hence a larger doublelayer is produced. Zisman [1932] and Horne [1964] studied the effect of pressure on hydrated ions in salt solutions and concluded that pressure breaks up the order in the hydration atmospheres which surround the ions, thereby decreasing their effective radii.

According to Stern's theory, this decrease in the hydrated ion size should result in a compressed double layer. Lang [1967] found evidence of this phenomenon in his experiments as well when he measured the electrical resistivity of clay-water systems as a function of pressure. He attributed the anomalous results to a pressure-induced deterioration of the adsorbed water, the diffuse double layer.

In considering the thermal conductivity of a sediment and its variation with pressure, it is advantageous to look at the pressure effects upon each phase separately. Bridgman [1949] has found that the thermal conductivity of water is primarily a function of density. As its density increases with increasing pressure, so does 1 ts thermal conductivity. He also studied the pressure dependence of this property for solids, both metals and nonmetals, and reported it to be much less than that upon the liquid phase. Since these sediments consist primarily of water, with porosities ranging from 0.70 to 0.88 , and since the effect of pressure upon the thermal conductivity of the solid matrix is minimal, any variation in sediment thermal conductivity with pressure is expected to reflect the pressure effects upon the liquid phase alone.

\section{Temperature Effects}

Mitchell [1976] has examined the deformation behavior of soils from the perspective of a rate process, where the theory of absolute reaction rates [Glasstone et al., 1941] is utilized to interpret soil behavior. This rate process theory, which is based on statistical mechanics, describes a time-dependent rearrangement of particles. It states that activation energies and related creep rates increase with temperature and that creep rate increases with increasing clay content. It was therefore expected that the clay samples which were exposed to high temperatures in this study would be susceptible to significant compaction or consolidation during the actual tests. The purpose of our work was not to determine the stress-strain propertles of various sediment types when subjected to certain 
loads and temperatures but, rather, to measure permeability and thermal conductivity at a series of prescribed water contents. The stresses required to consolidate a sample to a specifled porosity could not be accurately determined because of friction between the loading piston and the pressure vessel seals (see Figure 1 ). This piston, which was pushed through the top cap of the pressure cell and which exerted an axial stress on the sample, was equipped with spacers to prevent it from compacting beyond a predetermined distance. Any tendency for the sample to consolidate due to an accelerated, temperature-induced creep process was counteracted by an immediate relaxation in vertical stress. Therefore, all samples, including the high-temperature clays, are assumed to have maintained a constant vold ratio throughout the testing procedure.

One possible effect of temperature is the chemical alteration of a sediment. Miller [1967] has attempted to correlate the chemical-mineralogical changes of vartous sediment types with depth and duration of burial, pressure, and temperature. of the four sediment types analyzed in this study, his findings show that the one most susceptible to diagenesis is smectite. The transformation of smectite to illite has been well documented [Weaver, 1979]. Burst [1969], in studying Gulf Coast clays, has also recorded a gradual transformation of smectites into ilittes with increasing depth and temperature. This diagenesis, however, may only occur provided there is a sufficient source of potassium in the sediment. Illite is produced when potassium becomes lodged between the contracting layers of smectite. Khitarov and Pugin [1966] confirmed this condition by subjecting a number of montmorillonite samples to elevated temperatures. For samples containing only trace amounts of potassium, no detectable amount of illite was formed. For samples moistened beforehand with a 10 solution of potassium chloride, however, a smectite to illite transformation was easily initiated. The deep-sea smectite samples tested in this study did not contain any detectable amount of potassium, and consequently, no thermal alteration was expected. An Xray diffraction analysis conducted with these smectite samples prior to and after exposure to a test temperature of 2200 revealed no mineralogical changes and confirmed our assumption.

Seyfried and Thornton [1981] have conducted experimental and theoretical investigations studying thermally induced chemical alterations of illitic clays. Analyses of seawater chemistry during both their $2000 \mathrm{C}$ and $3000 \mathrm{C}$ tests showed concentrations of magnesium in solution to decrease and concentrations of potassium to increase. This process is interpreted as signifying the formation of smectite as a precipitate. On the basis of changes in solution chemistry, they conclude that illite, when exposed to temperatures above $2000 \mathrm{C}$, is replaced in part by smectite.

For siliceous and calcareous sediments, some diatoms and foraminifera, respectively, go into solution as temperatures are increased, until the pore fluid becomes saturated. This saturation level is very sensitive to temperature variatons. Adelseck et al. [1973] have reported that substantial precipitation of calcite occurred in a nannofossil ooze when exposed to $3000^{\circ}$ for 1 month. They found no significant reaction, however, at $2000^{\circ}$. Mtiller [1967] also notes that the transitional zone between diagenesis and metamorphism, where pronounced mineralogical changes begin to occur in biogenic oozes, is not reached until a critical transition temperature of $3000 \mathrm{C}$ is attained. Testing at this temperature was beyond the scope of this study, and, therefore, metamorphic changes were not considered.

A comparative study of compositional variations before and after exposure to elevated

temperatures showed no evidence of changes for any of the four sediment types of interest. It appears from previous work, however, that increasing our maximum experimental testing temperature from $2200 \mathrm{C}$ to $3000 \mathrm{C}$ would have dramatically accelerated chemical reaction kinetics and would have produced substantial changes in mineralogy.

The effect of temperature upon the diffuse double layer is now examined as a possible cause of permeabllity changes. Again, the biogenic samples, having no substantial double layer, are not expected to exhibit a change in absolute permeability with temperature. The absolute permeability ( $\mathrm{K}_{\mathrm{abs}}$ ) incorporates a temperature correction for the viscosity of seawater and carries the units of length squared:

$$
\mathrm{K}_{\mathrm{abs}}=\mathbf{k} \frac{v}{g}
$$

where $\mathrm{k}$ is the sediment permeability, $\nu$ is the kinematic viscosity of pore fluid, and $g$ is the gravitational constant.

Referring to equation ( $A I$ ) once again, temperature is a variable which proportionally influences the size of the double layer, all other factors remalning constant. An increase in temperature, however, also produces a corresponding decrease in the dielectric constant. Mitchell [1976] notes that the behaviors of these two parameters tend to cancel each other out within the temperature range of $00-600^{\circ}$, with the product $T E$ showing little variation with temperature. Values for dielectric constant have been presented by Lawson and Hughes [1963] at higher temperatures and pressures, however, and their data show approximately a 308 decrease in the product $T E$ when the temperature increases from 200 to $200{ }^{\circ} \mathrm{C}$ at a pressure of $60 \mathrm{MPa}$. According to equation (Al), this condition could reduce the size of the double layer by as much as $15 \%$. weaver [1979], in discussing temperature-1nduced ion mobilization, states that heat accelerates chemical changes and increases the solubility of minerals. This process should increase the ion concentration surrounding the clay particles and contribute to a reduction in the double layer size as well.

One parameter which is not considered in the Gouy-Chapman theory or in the modified approach of stern [1924] is the effect of solution $\mathrm{pH}$ on the diffuse double layer. Hydroxyl compounds $\left(\mathrm{OH}^{-}\right)$, often exposed on the surface of clay particles, have a greater tendency to dissociate 


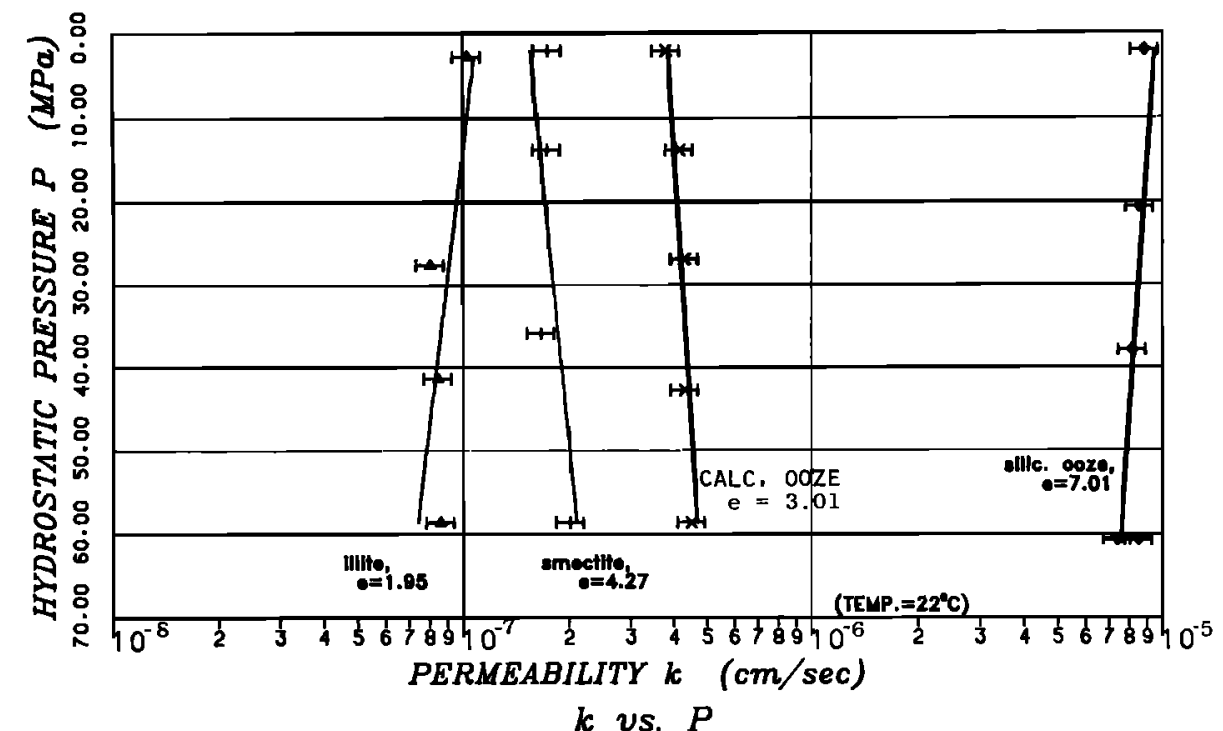

Fig. 2. Plot of permeability versus hydrostatic pressure for all four sediment types at room temperature and constant void ratio.

as the solution $\mathrm{pH}$ increases:

$$
\mathrm{SiOH} \rightarrow \mathrm{SiO}^{-}+\mathrm{H}^{+}
$$

As more $\mathrm{H}^{+}$ions go into solution, the effective negative charge of the particle increases, and a larger number of cations is required to satisfy the charge. Hence an increased solution $\mathrm{pH}$ results in an extended double layer. Bischoff and Seyfried [1978] have studied the effect of temperature on the $\mathrm{pH}$ of seawater. They report a gradual decrease in $\mathrm{pH}$ from 7.6 at $25 \mathrm{oC}^{\mathrm{C}}$ to 6.1 at 2200 , followed by a sharp decline to 2.5 at a temperature of $3500^{\circ} \mathrm{C}$. Thus for the temperatures of interest in this study, there is a gradual decrease in seawater $\mathrm{pH}$ which should result in a gradual contraction in the double layer size.

The above investigations suggest again, as in the case of the variable pressure analysis, that increasing temperatures tend to compress the size of the diffuse double layer. Indeed, Lang [1967] discovered anomalous values of electrical conductivity for clay-water systems as temperature was increased. This behavior is similar to that which he found from his variable pressure analysis. Specifically, an increase in temperature promotes a breakdown of the adsorbed water.

Data displaying the effect of temperature upon the thermal properties of rocks have been summarized by clark [1966]. This information illustrates that the thermal conductivities of most rocks decrease gradually with increasing temperature up to $3000 \mathrm{C}$. Keenan et al. [1978], on the other hand, report that the thermal conductivity of water increases with temperature until it reaches a maximum at about $1500 \mathrm{C}$; it then begins to decrease with increasing temperature. Some of these latter data on water are included in Figures 17 and 18. The temperature at which its thermal conductivity is a maximum shifts slightly as the hydrostatic pressure changes. As in the case with the variable pressure analysis, the effect of temperature upon the thermal conductivity of the sediments is expected to be dominated by the behavior of the liquid constituent alone.

\section{Results}

With pressure. Evidence has been cited from previous scientific investigations, both analytical and empirical, which suggests that the double layers present in clays actually break down with increasing hydrostatic pressure. our first series of laboratory tests was designed to determine what effect the existence of this phenomenon would have on the permeability of ocean sediments. One sample of each of the four sediment types was exposed, at room temperature, to pressures ranging from 2 to $60 \mathrm{MPa}$, and the results are shown in Figure 2. The experimental accuracy is approximately \pm 108 , and the lines, which were obtained from a conventional regression analysis, have slopes which are within this accuracy of being vertical. As mentioned earlier, the biogenic samples have no significant double layer, and consequently, no variation with pressure was expected. The results, however, show negligible pressure effects upon the permeabilities of the clays as well.

Permeability is affected by the viscosity of the permeating medium which, in this case, is seawater. Horne [1965] shows approximately a 18 decrease in the relative viscosity of an aqueous, $0.5 \mathrm{M} \mathrm{NaCl}$ solution at $250^{\circ} \mathrm{C}$ and $60 \mathrm{MPa}$ when compared to values at $0.1 \mathrm{MPa}(1 \mathrm{~atm})$. This viscosity correction for pressure was not applied, since $1 t$ is well within the accuracy of the measurenent. It is interesting to note that the viscosity of water at room temperature, unlike that of any other liquid, decreases with increasing pressure, again implying an effective breakdown in its structure.

The results of the thermal conductivity versus pressure tests for all four sediment types are depicted in Figure 3. The data are seen to parallel closely the behavior of water alone as a function of pressure [Lawson et al., 1959]. The 


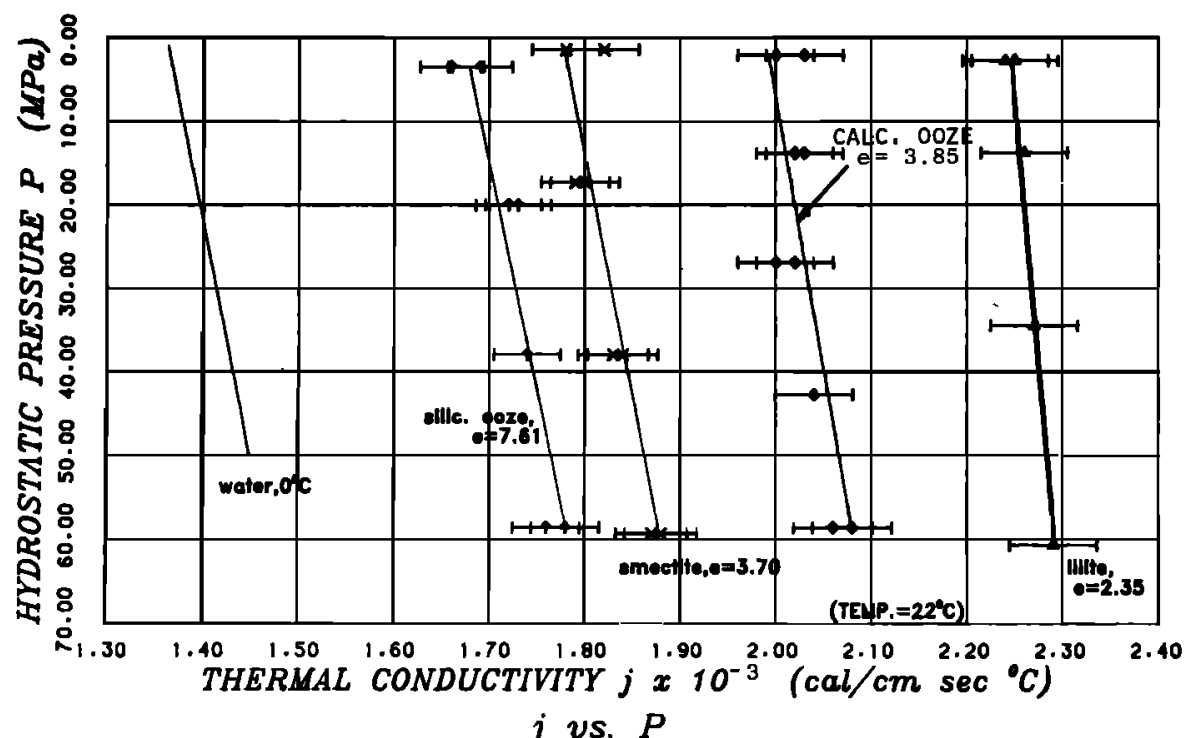

Fig. 3. Thermal conductivity versus hydrostatic pressure for all four sediment types at room temperature and constant void ratio.

slopes of these regression analysis lines vary slightly with void ratio, approaching the slope of the data for water as sediment void ratio increases. This information can be translated into a thermal conductivity correction factor for hydrostatic pressure as a function of porosity and is plotted as curve $A$ in Figure 4. The value obtained from curve $A$ for a specific porosity should be added to the sediment thermal conductivity measured at atmospheric pressure for every $1000 \mathrm{~m}$ of water depth required to duplicate the proper in situ pressures. It can be seen that the correction term decreases with decreasing porosity. This behavior is expected, since the influence of the liquid phase upon sediment thermal conductivity also declines with decreasing porosity.

The conventional shipboard correction factor for pressure, suggested by Ratcliffe [1960], is 18 per $1000 \mathrm{fm}(1830 \mathrm{~m})$. To illustrate this method, the correction is applied to the thermal conductivity values for siliceous ooze at $220 \mathrm{C}$ which are plotted in Figure 16 as a function of porosity. Line $B$ in Figure 4 illustrates this example and shows how the thermal conductivity is predicted to change at various porosities for pressure increments of $10 \mathrm{MPa}$. This pressure correction increases with decreasing porosity and directly opposes the trend derived from the data in Figure 3 and plotted as curve $A$ in Figure 4. We suggest a revised relationship to correct thermal conductivities to in situ pressure. within a sediment porosity range of 1.0 to approximately 0.78 (vola ratios of infinity to 3.60 ), a mean value for the pressure correction can be obtained from the data shown in curve $A$.

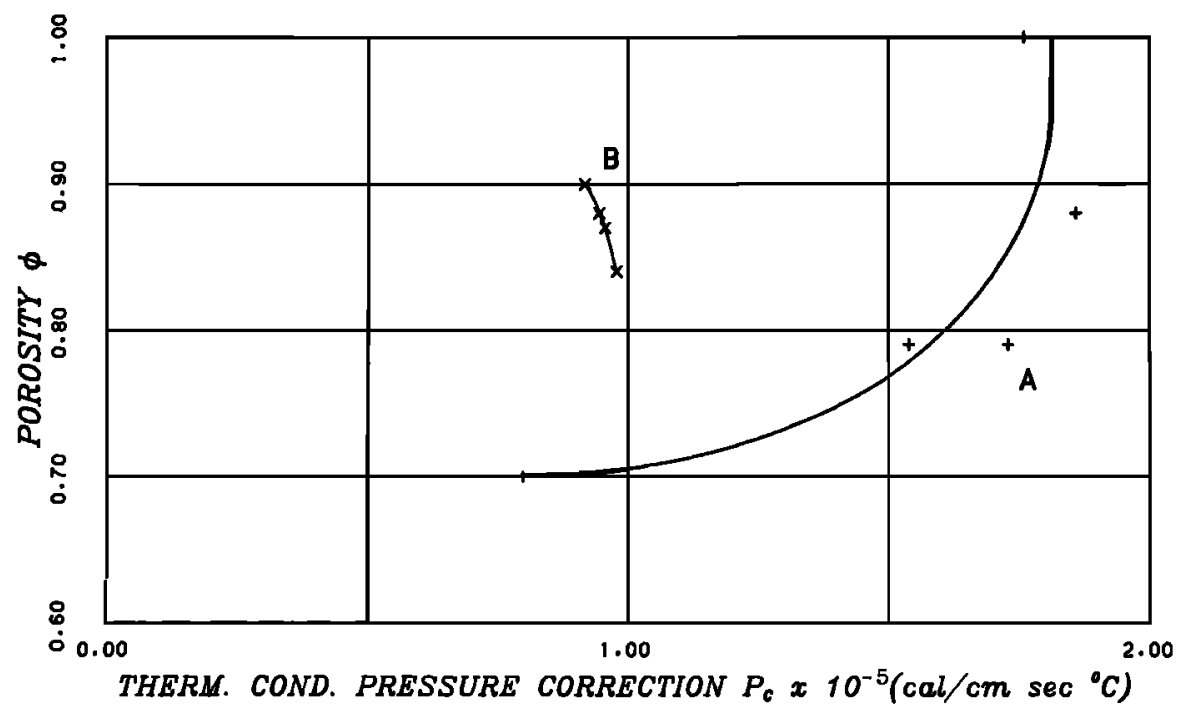

Fig. 4. Thermal conductivity pressure correction versus porosity. Curve A is a plot of data obtained from the slopes of the lines in Figure 3. The data plotted for line B were obtained by using the conventional pressure correction method [Ratcliffe, 1960] on siliceous ooze. 


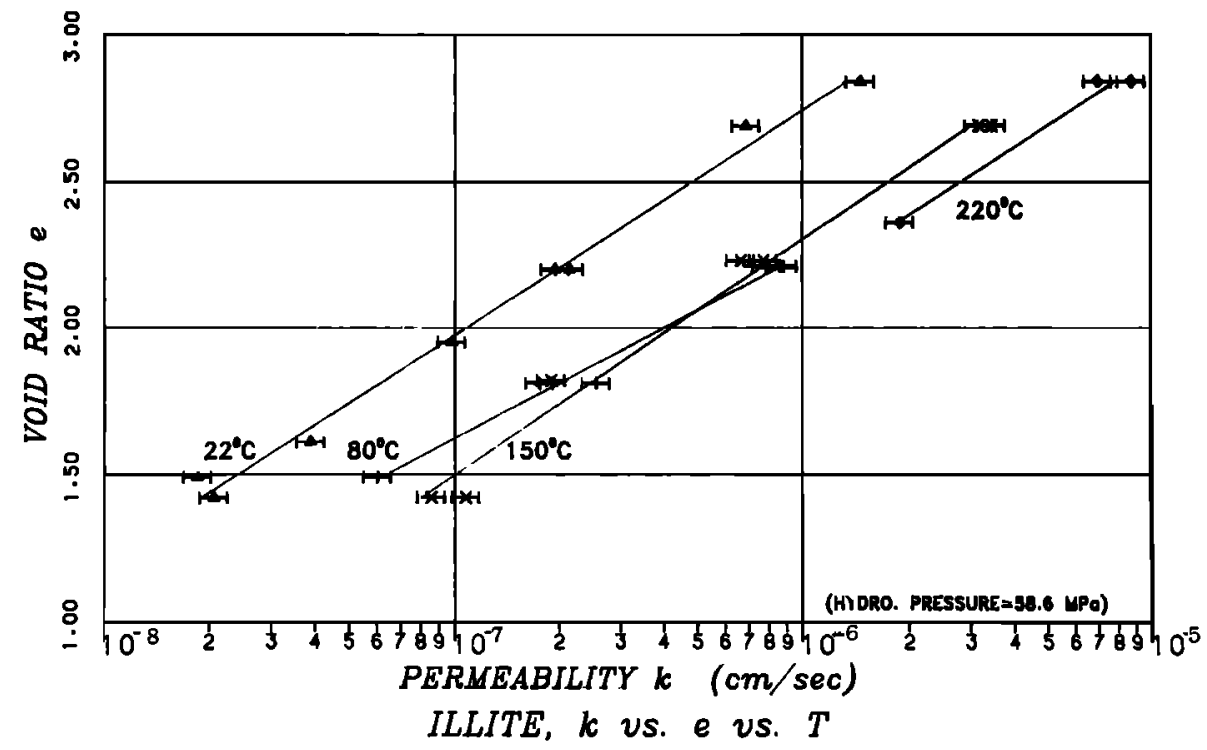

Fig. 5. Permeability versus void ratio at four temperature intervals for illite. Hydrostatic pressure is constant at $58.6 \mathrm{MPa}$.

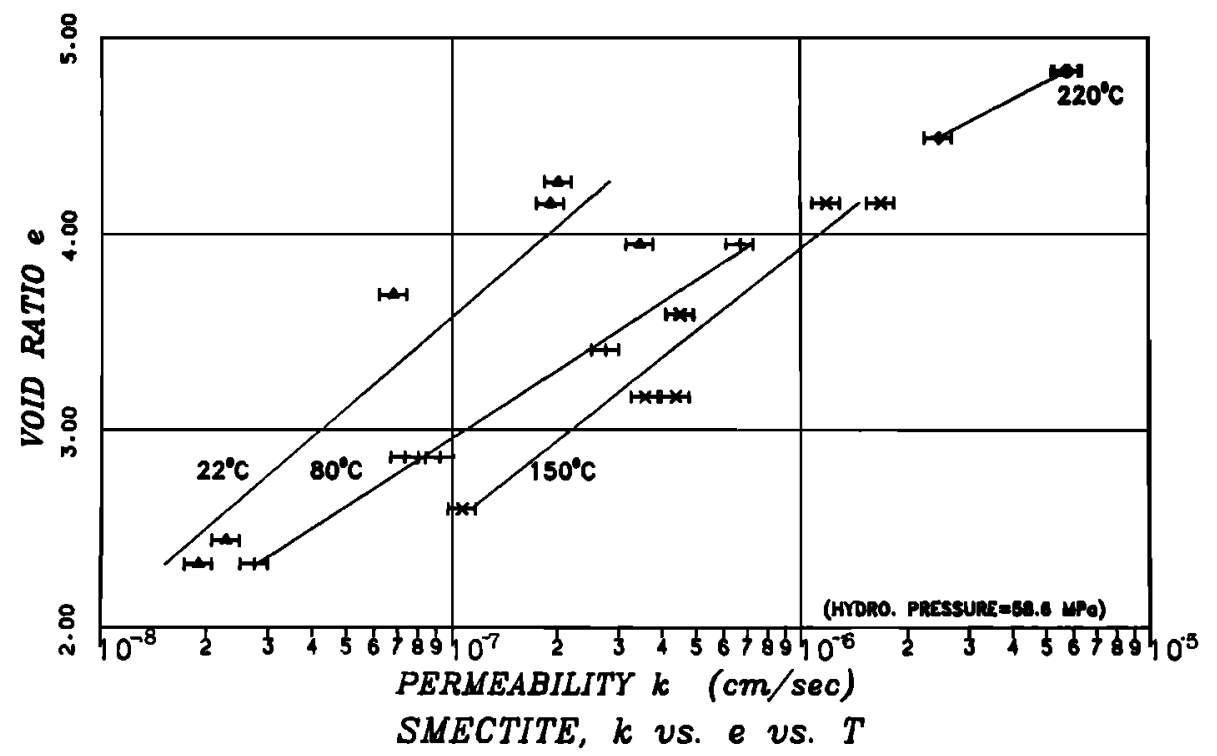

Fig. 6. Permeability versus void ratio at four temperature intervals for smectite. Hydrostatic pressure is constant at $58.6 \mathrm{MPa}$.

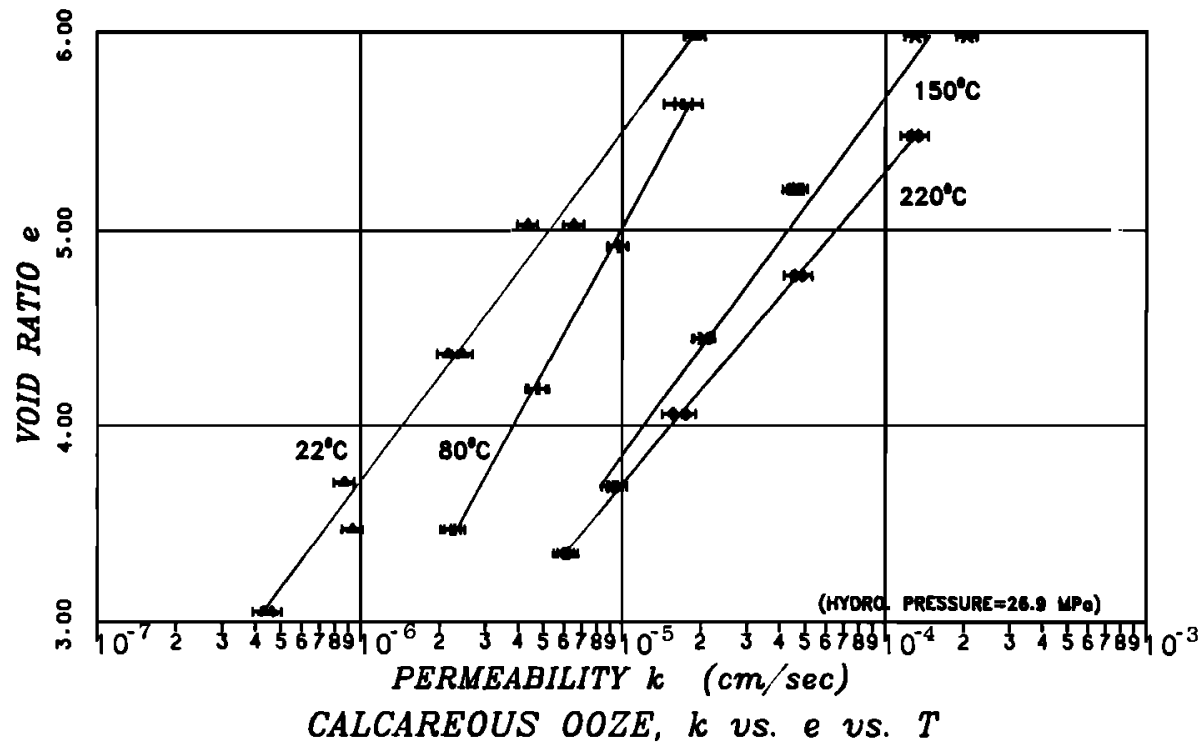

Fig. 7. Permeability versus void ratio at four temperature intervals for calcareous ooze. Hydrostatic pressure is constant at $26.9 \mathrm{MPa}$. 


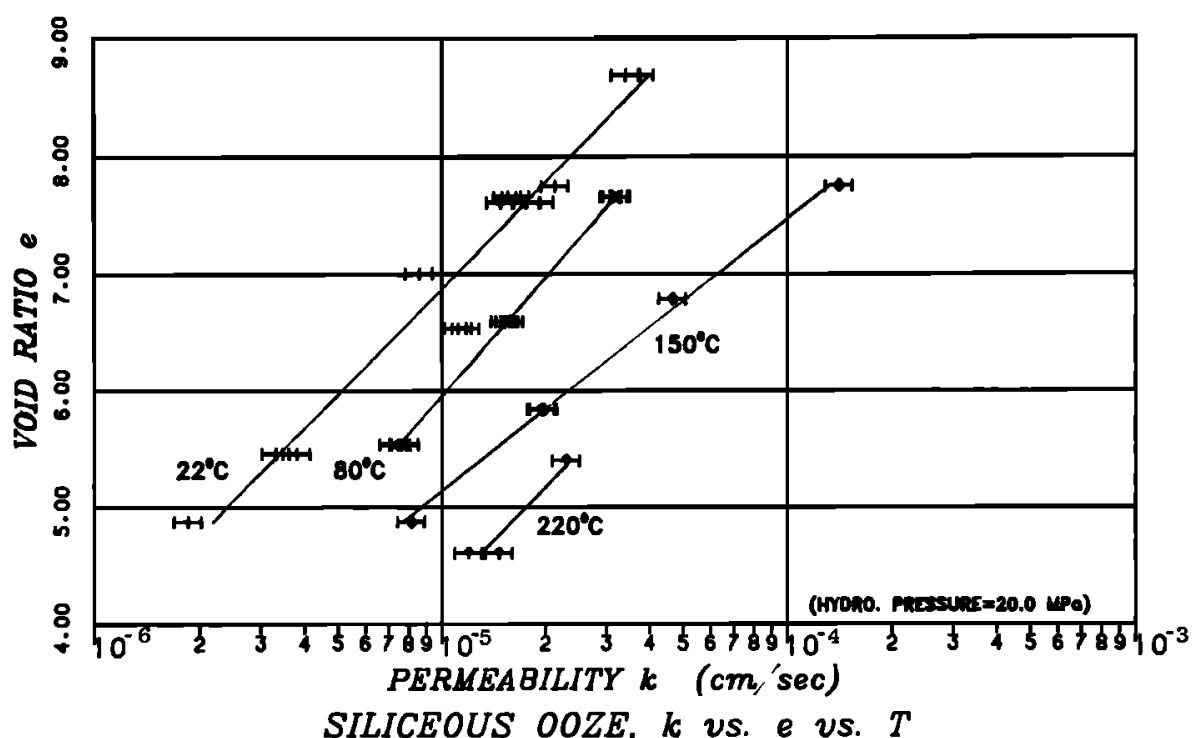

Fig. 8. Permeability versus void ratio at four temperature intervals for siliceous ooze. Hydrostatic pressure is constant at $20.0 \mathrm{MPa}$.

This value is $1.72 \times 10^{-5} \mathrm{cal} / \mathrm{cm} s$ oc 17.2 $\mathrm{mW} / \mathrm{m}$ OC) per $1000 \mathrm{~m}$ of water depth which should be added to the thermal conductivity measured at atmospheric pressure.

$$
\begin{aligned}
\begin{aligned}
\text { pressure corrected } \\
\text { thermal conductivity }
\end{aligned} & \begin{aligned}
& \text { thermal conductivity } \\
&(\text { at } 1 \text { atm })
\end{aligned} \\
+\left(\frac{1.72 \times 10^{-5} \mathrm{cal}}{\mathrm{cm} \mathrm{s}^{0} \mathrm{C}}\right) & \left(\frac{\text { Watep }}{1000 \mathrm{~m}}\right)
\end{aligned}
$$

Thus a sediment sample obtained from a water depth of $2500 \mathrm{~m}$ will require that a value of 4.30 $x 10^{-5} \mathrm{cal} / \mathrm{cm} \mathrm{s}$ oc $\left(18.0 \mathrm{~mW} / \mathrm{m}{ }^{\circ} \mathrm{C}\right)$ be added to the shipboard thermal conductivity.

With temperature. The results of the permeability tests as a function of temperature are displayed in Figures 5-8. These data were corrected for pore fluid viscosity effects [Keenan et al., 1978], and corresponding graphs of absolute permeability are presented for each sediment type in Figures 9-12. As in the case with the variable pressure analysis, a reduction of the double layer for the clays at elevated temperature had been anticipated from the literature previously cited. The results, however, show no obvious dependence of absolute permeability upon temperature. The biogenic samples depict the same type of behavior.

The results of the thermal conductivity tests performed at variable temperatures are depicted in Figures 13-16. These data reflect the response of the liquid phase alone to changes in temperature. Figures 17 and 18 illustrate this point by comparing the data obtained from the four sediment types at constant void ratios (values taken from approximating curves) to those

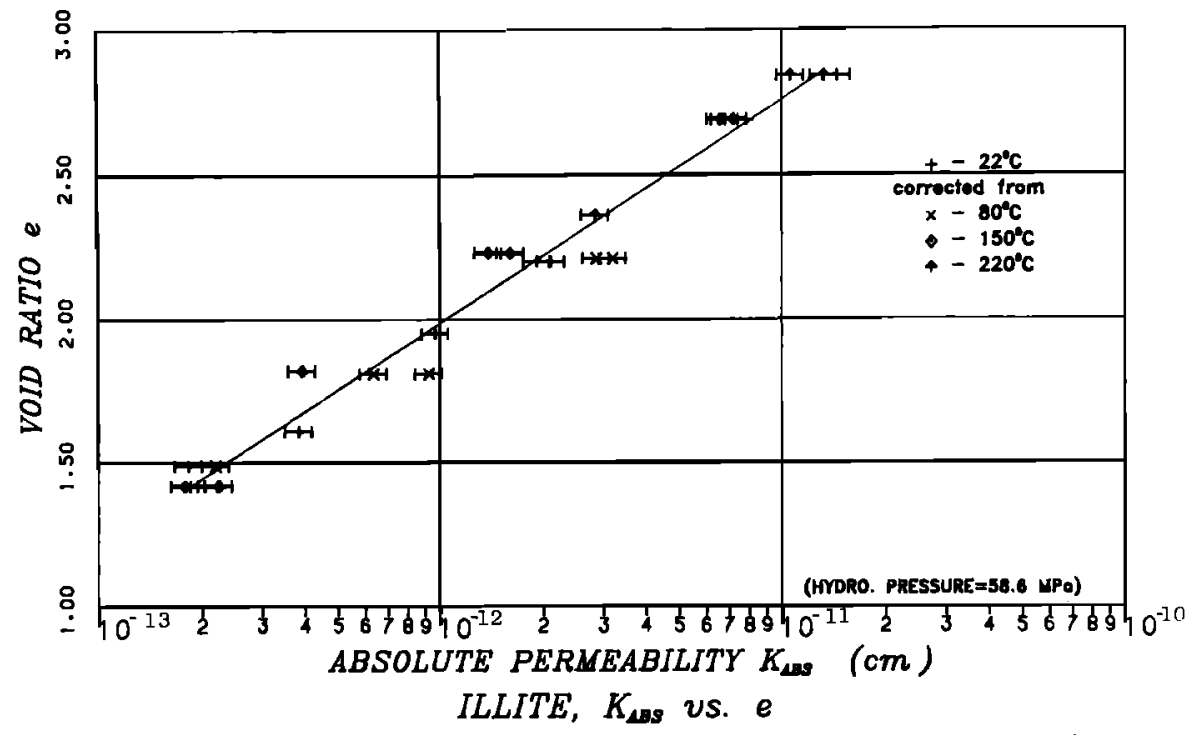

Fig. 9. Absolute permeability (corrected for temperature) versus void ratio for illite. Hydrostatic pressure is constant at 58.6 MPa. $\mathrm{K}_{\mathrm{abs}}=101.30 \mathrm{e}-14.57 \mathrm{~cm} 2$ 


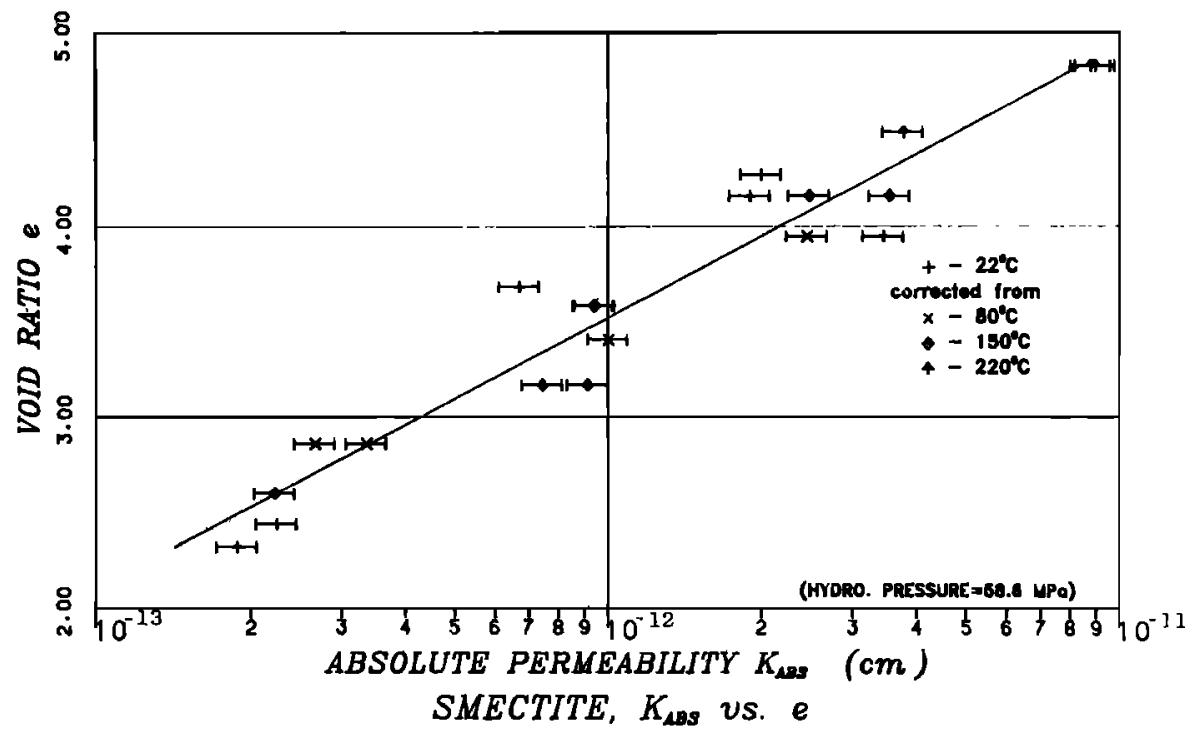

F1g. 10. Absolute permeability (corrected for temperature) versus void ratio for smectite. Hydrostatic pressure is constant at $58.6 \mathrm{MPa}$. $\mathrm{K}_{\mathrm{abs}}=100.72 \mathrm{e}-14.55 \mathrm{~cm} 2$

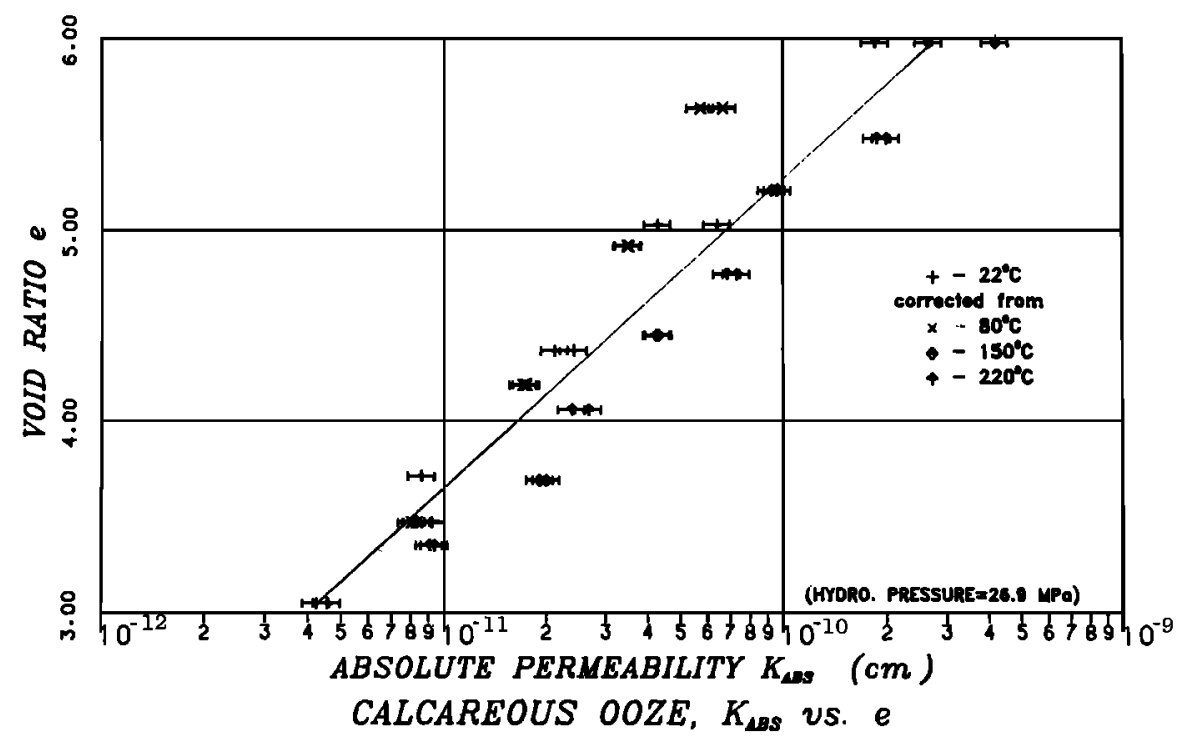

Fig. 11. Absolute permeability (corrected for temperature) versus vold ratio for calcareous ooze. Hydrostatic pressure is constant at $26.9 \mathrm{MPa}$. $\mathrm{K}_{\mathrm{abs}}=100.62 \mathrm{e}-13.27 \mathrm{~cm} 2$.

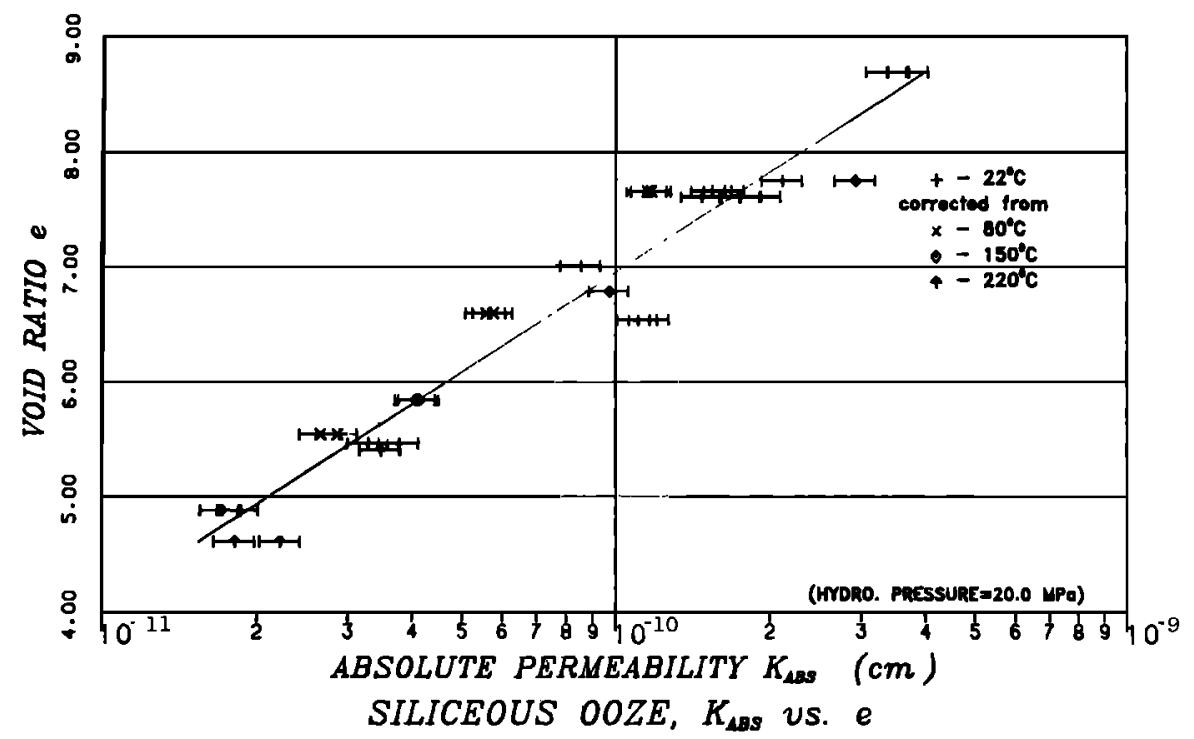

Fig. 12. Absolute permeability (corrected for temperature) versus void ratio for siliceous ooze. Hydrostatic pressure is constant at $20.0 \mathrm{MPa}$.

$K_{a b s}=100.35 e-12.43 \mathrm{~cm}^{2}$ 


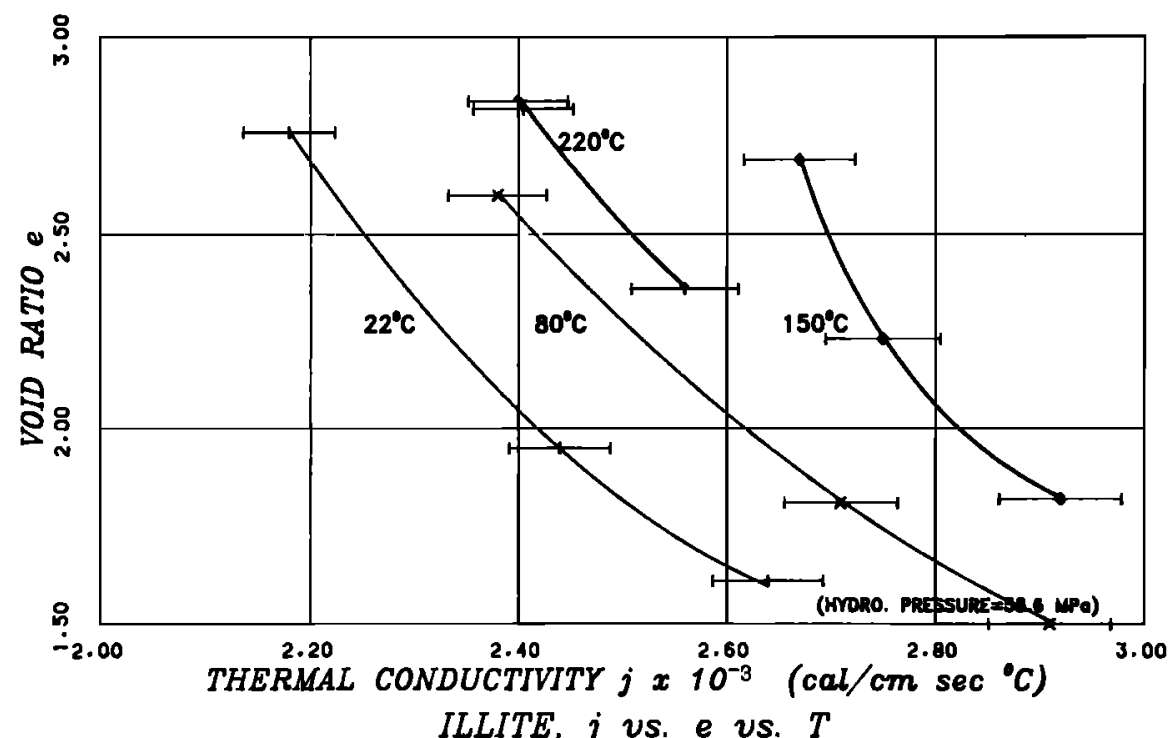

Fig. 13. Thermal conductivity versus void ratio at four temperature intervals for illite. Hydrostatic pressure is constant at $58.6 \mathrm{MPa}$.

for water. It is reasonable to assume that the relative influence of the liquid constituent will decrease as the porosity decreases.

with consolidation. After initial pressurization and heat-up, each test specimen was consolidated through a series of decreasing porosities in order to simulate compaction through the sediment column. int each prescribed stage the permeability and thermal conductivity were measured. Bryant et al. [1975] have determined the permeability of a number of fine-grained sediments and have developed empirical equations which relate permeability to porosity as a function of grain size. The results of our permeability tests performed on the two clays of interest closely approximate those of this prior study performed with unconsolidated marine sediments. Expressions for absolute permeability versus void ratio, which were derived from the data plotted in Figures 9 and 10, are listed below. These values of $K_{a b s}$ are independent of both hydrostatic pressure and temperature:

$$
\begin{aligned}
& k_{\text {abs }}=101.30 \mathrm{e}-14.57 \mathrm{~cm}^{2} \text { (illite) } \\
& k_{a b s}=10^{0} .72 e^{-14.55} \mathrm{~cm}^{2} \text { (smectite) }
\end{aligned}
$$

Similarly, J. Crowe and A.J. Silva (unpublished manuscript, 1982) present results of permeability tests run on consolidated biogenic sediments obtained from the equatorial Pacific. Their results show a more gradual decline in permeability with decreasing void ratio than do the data on clays. Figures 11 and 12 present our permeability data obtained from the two biogenic samples as a function of void ratio, and equations describing these relationships are listed below. Again, these results agree very well with the work reported by J. Crowe and A.J.

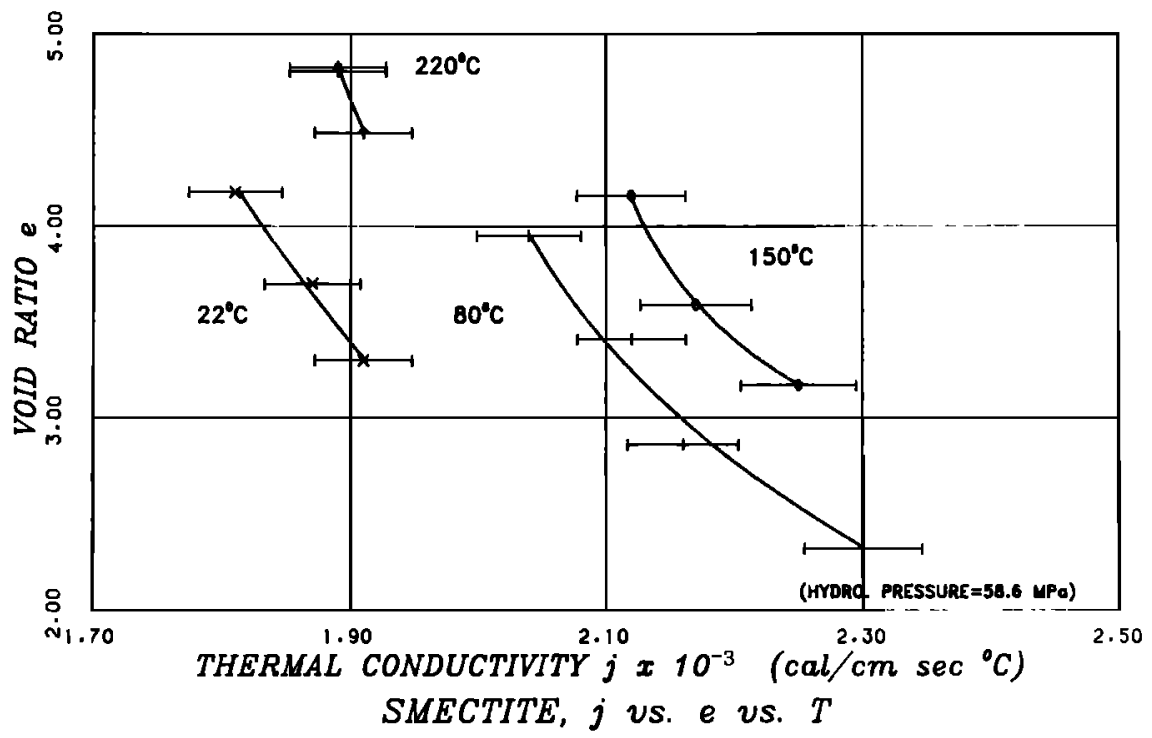

Fig. 14. Thermal conductivity versus void ratio at four temperature intervals for smectite. Hydrostatic pressure is constant at $58.6 \mathrm{MPa}$. 


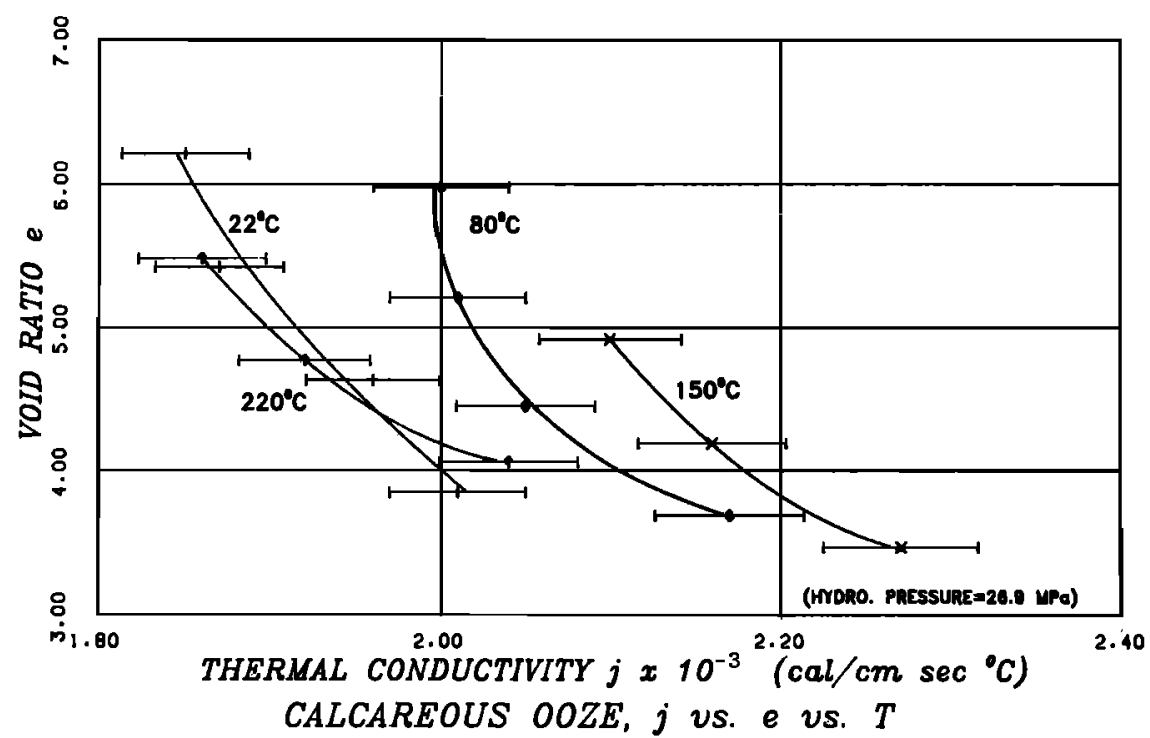

Fig. 15. Thermal conductivity versus void ratio at four temperature intervals for calcareous ooze. Hydrostatic pressure is constant at $26.9 \mathrm{MPa}$.

Silva [unpublished manuscript, 1982] on similar sediments.

$$
\begin{aligned}
& \mathrm{K}_{\mathrm{abs}}=100 \cdot 62 \mathrm{e}-13.27 \mathrm{~cm}^{2} \quad(\text { calcareous ooze }) \\
& \mathrm{K}_{\mathrm{abs}}=100.35 \mathrm{e}-12.43 \mathrm{~cm}^{2} \text { (siliceous ooze) }
\end{aligned}
$$

The results of the thermal conductivity versus void ratio experiments for the four sediment types are presented in Figures 13-16. The expected trend of increasing conductivity with decreasing water content is consistent with previous work [Ratcliffe, 1960]. The graphs illustrate how the solid phase constituents, with their higher thermal conductivities, begin to Influence the two-phase conductivities of the sediments to a greater degree as porosity declines. Various mixture theories have been proposed to predict the thermal conductivity of saturated porous media in terms of the constituent properties and the porosity. Both parallel and series conduction models, along with various combinations of the two, have been developed and are examined by Bear [1972]. The predictive value of these relationships depends upon an adequate estimation for the thermal conductivity of the sediment skeleton. Although Horai [1971] has measured the thermal properties of a large number of rock-forming minerals, determining the conductivity of the actual solid matrix has continued to be a problem for investigators. Hadley et al. [1983] have presented a best fit curve relating thermal conductivity to porosity for a wide variety of geologic materials, ranging from crustal rocks to soft sediments. This study indicates that the relationship between the two is best approximated by some combination of the parallel and series models.

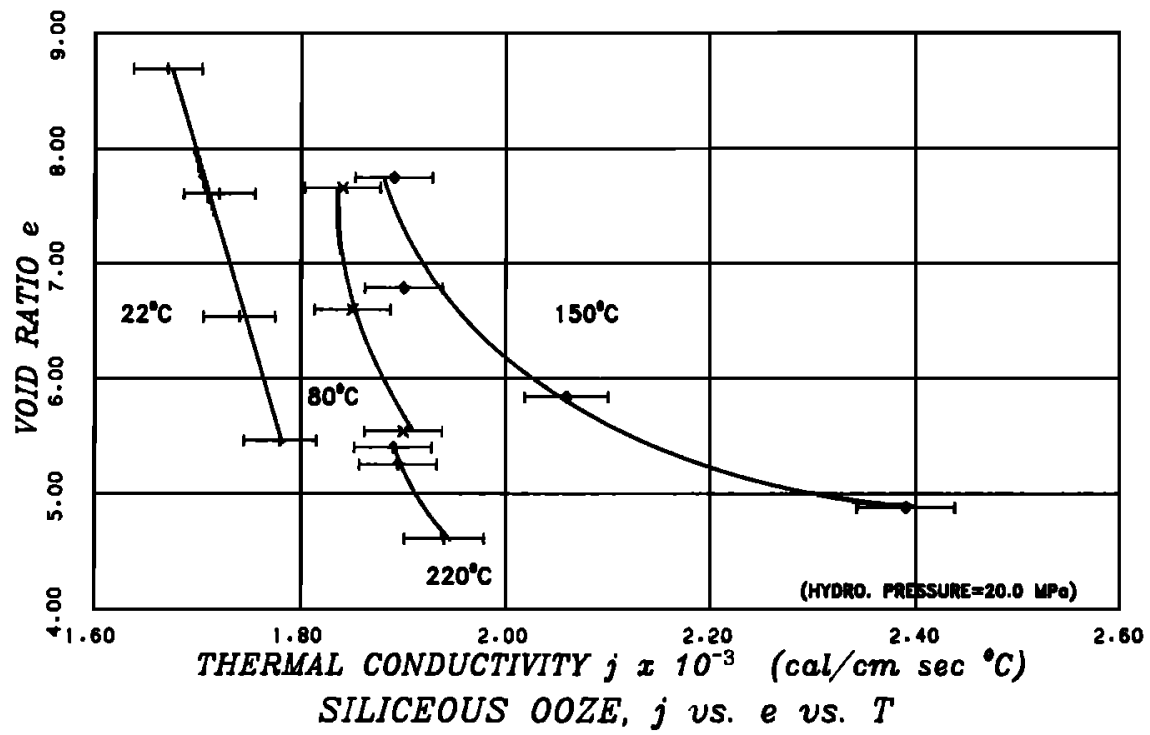

Fig. 16. Thermal conductivity versus void ratio at four temperature intervals for siliceous ooze. Hydrostatic pressure is constant at $20.0 \mathrm{MPa}$. 


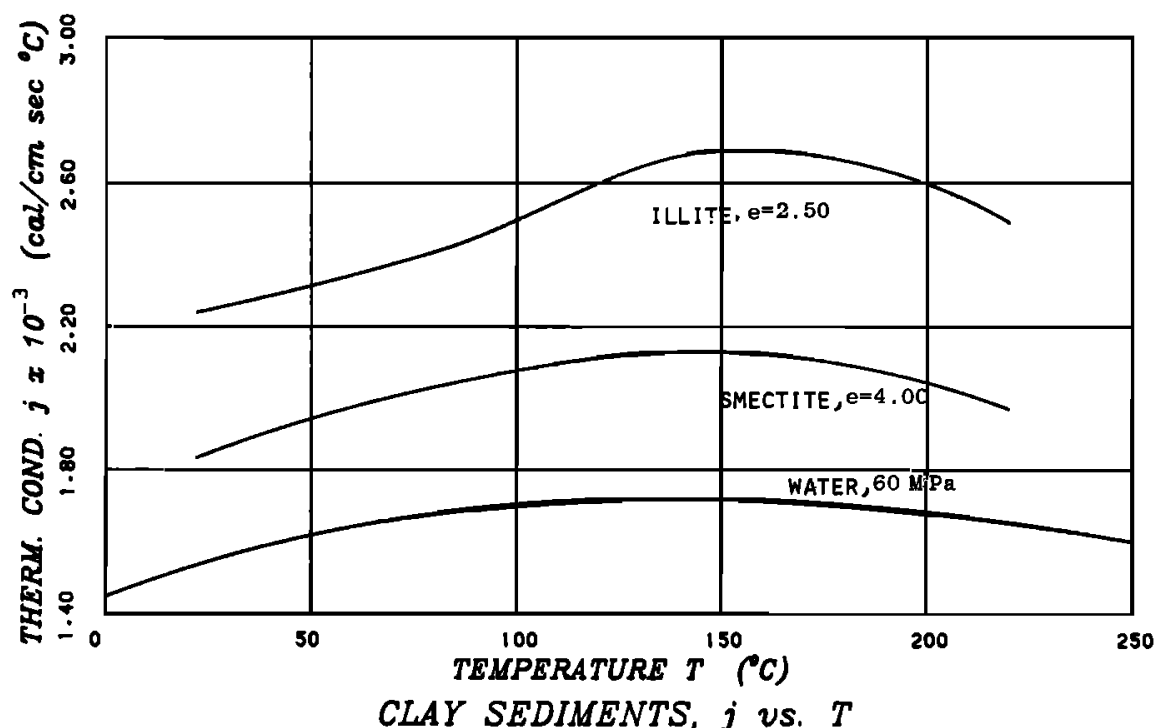

Fig. 17. Thermal conductivity versus temperature for both clays at constant void ratio compared to water at $60 \mathrm{MPa}$ hydrostatic pressure.

Such a combination was employed in developing a set of expressions for thermal conductivity versus void ratio as a function of temperature. The data shown in Figures $13-16$ can be roughly approximated by a logarithmic relationship for the thermal conductivity $j$ at each temperature interval. Thls equation takes on the general form

$$
\log j=m e+b
$$

where $e$ is the void ratio and $m$ is the slope of the line resulting from a conventional regression analysis of the data. Up to a temperature of $1500 \mathrm{C}$, the slope is found to increase with increasing temperature in a nearly linear manner and another relationship is developed between $m$ and $T$ : where the values for $a$ and $c$ are constant. The final expressions for the four sediment types are listed below:

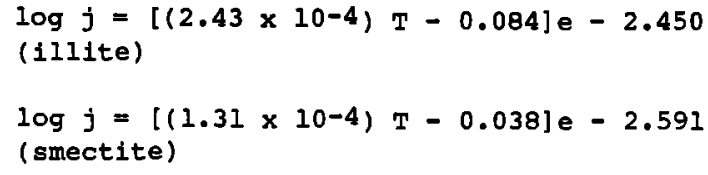

$\log j=\left[\left(5.03 \times 10^{-5}\right) \mathrm{T}-0.022\right] \mathrm{e}-2.605$ (calcareous ooze)

$\log J=[(3.57 \times 10-5) T-0.019] \mathrm{e}-2.618$ (siliceous ooze)

$$
m=a T+c
$$

$j$ in cal/cm s oc, $T$ in oc

$$
\left(220^{\circ} \leq \mathrm{T}<1500 \mathrm{C} ; 1.5 \leq \mathrm{e} \leq \mathrm{B} .8\right)
$$

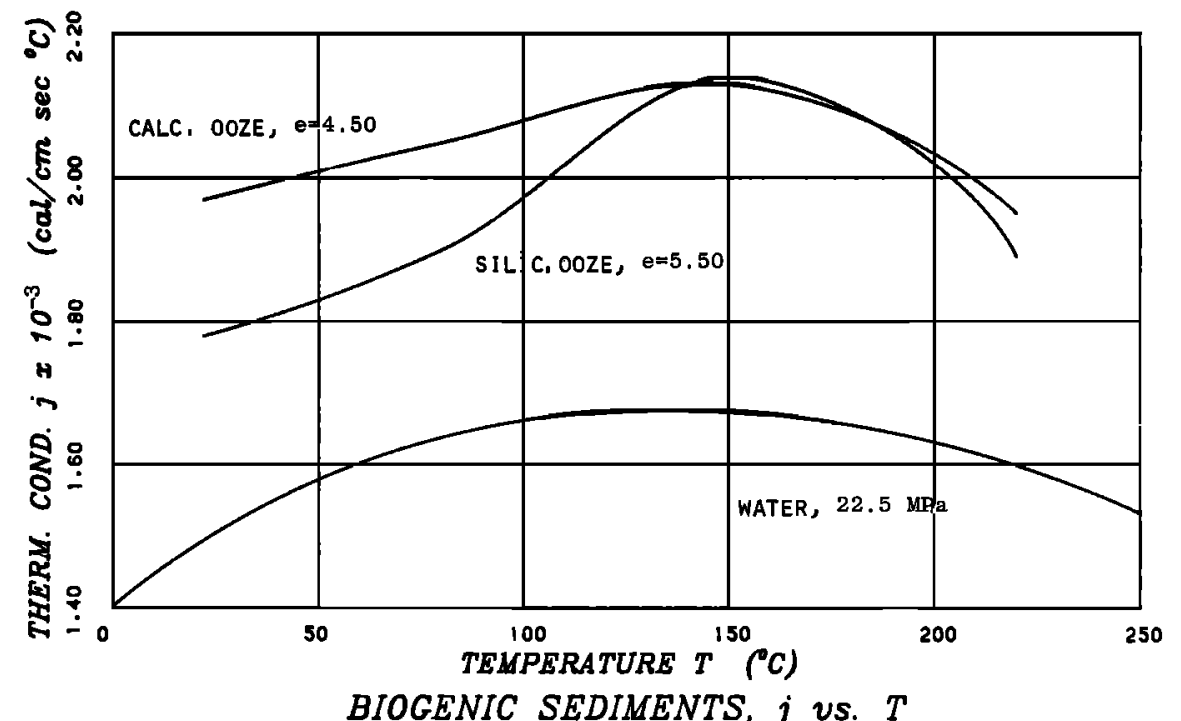

Fig. 18. Thermal conductivity versus temperature for both biogenic sediments at constant void ratio compared to water at $22.5 \mathrm{MPa}$ hydrostatic pressure. 
The above equations were derived from our experimental data and are only applicable for a relatively narrow range of porosities which were relevant to this study. Since the analysis assumes an increase in thermal conductivity with increasing temperature, the equations should not be used when sediment temperatures exceed approximately $1500 \mathrm{C}$.

\section{Discussion}

The results of both the permeability and thermal conductivity tests as a function of void ratio are consistent with previous laboratory studies performed by other investigators on similar sediments. This agreement is important, since it lends confidence to our experimental technique and apparatus. No inconsistencies due to inherent differences in laboratory equipment design were discovered.

In considering biogenic samples, it appears that the solld matrix remains unaffected by significant changes in hydrostatic pressure. Previous studies seem to indicate that in the case of clays, the diffuse double layer is directly affected by large variations in pressure and temperature. The existence of this phenomenon was not confirmed in this study. As can be seen in the appendix, the size of the double layer is small when the pore fluid is seawater $(0.5 \mathrm{~N} \mathrm{NaCl})$. The value of $4.28 \mathrm{~A}$ calculated for $I$ is not much greater than the diameter of a water molecule, approximately $3 \mathrm{~A}$. Even if the double layer had contracted by 258 due to severe environmental conditions, its characteristic size would only have been reduced by about $1 \mathrm{~A}$. It seems unlikely that a reduction of this magnitude would appreciably effect sediment permeability when the average half-distance spacing between particles is $90 \AA$ (illite) or even $18 \mathrm{~A}$ (smectite). It is interesting to note, however, that at vold ratios of 1 or less corresponding to sediment thicknesses of 200-300 m, the double layer thickness and the particle half spacing for smectite are approximately the same. Within this lower porosity region, variations in double layer size would affect the vold volume to a greater degree. Thus some permeability dependence upon pressure may still be possible for sediments of lower void ratio than those considered in this study.

If the double layer of surficial sediments is indeed affected by hydrostatic pressure, there appears to be no discernible influence upon sediment permeability when the pore fluid is seawater. This conclusion shows that more conventional, back-pressured laboratory permeability tests performed on deep-sea sediments at much smaller hydrostatic pressures are adequate and that results can be extrapolated to high pressures. It fails, however, to offer a solution to the conflicting data described earlier regarding pore water velocities derived from heat flow measurements and from Darcy's law. It appears that other possible explanations, such as horizontal water movement or sample disturbance during coring [Abbott et al., 1981], will have to be considered further. Because of the high porosities encountered in these tests, pressure and temperature effects upon sediment thermal conductivities were found to be dominated by the behavior of the liquid phase. A simple pressure correction has been determined from experimental data and empirical equations have been developed which relate thermal conductivity to void ratio and temperature. If values of thermal conductivity are known at room temperature and at a few megapascals hydrostatic pressure, additional values at more severe environmental conditions can be predicted by utilizing these relationships.

The long-term chemical kinetics of diagenesis are difficult to reproduce in a laboratory and are not well understood. The duration of our tests with each specimen was approximately 14 days. Although Seyfried and Thornton [1981] found that the predominant thermal alteration of their illitic samples occurred during the first 2 weeks of testing, chemical changes continued for the entire duration of their 2-month-long experiments. The laboratory results of our tests performed at elevated temperatures may have limited predictive value because of possible temperature-1nduced diagenesis which persists over many months. Long-term physical properties experiments at relatively high temperatures would improve our understanding of this process.

Further test results obtained through a greater range of sediment porosities, extending particularly to lower values, would be helpful in analyzing the role of the solid matrix in determining sediment conductivity responses to large pressures and high temperatures. This information would facilitate the development of proper thermal conduction models and would extend our predictive capabilities to greater depths within the sediment column.

\section{Appendix: Double-Layer Computations [From van Olpen, 1977]}

The characteristic size of the double layer is defined as

$$
L=\left(\frac{\varepsilon B T}{8 \pi c s^{2} v^{2}}\right)^{\frac{1}{2}}
$$

where

$\varepsilon$ dielectric constant of the medium;

B Boltzmann's constant;

T temperature;

c electrolyte concentration;

$s$ unit electronic charge;

$v$ cation valence.

The thickness $I$ carries the units of length and is actually the center of gravity of the space charge adjacent to the clay surface.

\section{Illite}

$$
\begin{aligned}
& E_{\text {water }}=80 \quad \mathrm{BT}=0.4 \times 10-13 \text { ergs at } 170 \mathrm{C} \\
& \mathrm{s} \quad=4.80 \times 10-10 \mathrm{esu} \text { (electrostatic units) } \\
& \text { c } \quad=6.02 \times 1020 \mathrm{M} \text { ions } / \mathrm{cm}^{3} \\
& \mathrm{M} \quad=\text { molarity }=0.5 \mathrm{NaCl} \text { (seawater) } \\
& \text { c } \quad=3.01 \times 1020 \text { ions } / \mathrm{cm}^{3} \quad \mathrm{v}=1 \\
& L=\left(\frac{(80)\left(0.4 \times 10^{-13}\right)}{(8)(\pi)\left(3.01 \times 10^{20}\right)(4.80 \times 1010)^{2}(1)^{2}}\right)^{\frac{1}{2}}
\end{aligned}
$$


$=4.28 \times 10-8 \mathrm{~cm}$

$=4.28 \AA$ (thickness of double layer)

$\mathrm{d}=$ half the particle spacing $=\frac{e}{\mathrm{GA}_{\mathrm{s}}}$

where $A_{S}=$ specific surface $=0.80 \times 106 \mathrm{~cm}^{2} / \mathrm{g}$ $\mathrm{G}=$ specific gravity $=2.78 \mathrm{~g} / \mathrm{cm}^{3}$

let $e=$ void $\operatorname{rat} 10=2.0$

$d=\frac{2.0}{(2.78)\left(.80 \times 10^{6}\right)}=89.9 \times 10^{-8} \mathrm{~cm}$ $=89.9 \AA$

Smectite

$L=4.28 \AA$ (same as for illite)

$A_{s}=7.0 \times 10^{6} \mathrm{~cm}^{2} / \mathrm{g}$

$\mathrm{G}=2.74 \mathrm{~g} / \mathrm{cm}^{3}$

let $e=$ void ratio $=3.50$

$d=$ half the particle spacing

$$
\begin{array}{ll}
\frac{3.50}{(2.74)(7.0 \times 106)} & =18.2 \times 10-8 \mathrm{~cm} \\
& =18.2 \AA
\end{array}
$$

Acknowledgments. We are grateful to $M$. Bender for supplying us with calcareous samples from the Galapagos Spreading Center and to P. Lonsdale for his cooperation on the Gulf of California cruise where we obtained our siliceous samples. We would also like to thank $R$. Steinen for his Xray diffraction work on the clay spectmens. Support for the project was provided by the National Sclence Foundation grant OCE 79119426 and the Department of Energy in cooperation with Sandia Laboratories, contracts 13-2561 and 13-9927.

\section{References}

Abbott, D., W. Menke, M. Hobart, and R. Anderson, Evidence for excess pore pressures in southwest Indian Ocean sediments, J. Geophys. Res., 86, 1813-1827, 1981.

Adelseck, C. G., G. W. Geehan, and P. H. Roth, Experimental evidence for the selective dissolution and overgrowth of calcareous nannofossils during diagenesis, Geol. Soc. Am. Bull., 84, 2755-2762, 1973.

Anderson, D. R., C. D. Hollister, and D. M. Talbert (Eds.), Report to the Radioactive Waste Management Committee on the First International Workshop on Seabed Disposal of High-Level Wastes, Woods Hole, Massachusetts, Feb. 16-20, 1976, Rep. SAND76-0224, Sandia Lab., Albuquerque, N.M. ,April 1976.

Anderson, R. N., M. A. Hobart, and M. G. Langseth, Geothermal convection through oceanic crust and sediments in the Indian Ocean, Science, 204, 828-832, 1979.

Bear, J., Dynamics of Fluids in Porous Media, American Elsevier, New York, 1972.

Bischoff, J. L., and W. E. Seyfried, Hydrothermal chemistry of seawater from 250 to $3500 \mathrm{C}$, Am. J. Sci., 278, 838-860, 1978.

Bolt, G. H., Analysis of the validity of the GouyChapman theory of the electric double layer, J. Colloid Sci., 10, 206-218, 1955.

Bowles, J. E., Englneering Properties of Soils and Their Measurement, McGraw-Hill, New York, 1978.

Bridgman, P. W., The Physics of High Pressure, $G$. Bell, New York, 1949.

Bryant, w. R., w. Hottman, and P. Trabant, Permeability of unconsolidated and consolidated marine sediments, Gulf of Mexico, Mar. Geotech., 1, 1-13, 1975.

Burst, J. F., Diagenesis of gulf coast clayey sediments and its possible relation to petroleum migration, Am. Assoc. Pet. Geol. Bull., 53, 73-93, 1969.

Clark, S. P. (Ed.), Handbook of Physical Constants, Geological Soclety of America, Boulder, Colo., 1966.

Davis, E. E., and C. R. B. Lister, Heat flow measured over the Juan de Fuca Ridge: Evidence for widespread hydrothermal circulation in a highly heat transportive crust, J. Geophys. Res., 82, 4845-4860, 1977.

Glasstone, S., K. Laidler, and H. Eyring, The Theory of Rate Processes, McGraw-H111, New York, 1941.

Green, K. E., R. P. Von Herzen, and D. L. Williams, The Galapagos Spreading Center at 860w: A detailed geothermal fleld study, J. Geophys. Res., 86, 979-987, 1981.

Hadley, G. R., D. F. McVey, and R. Morin, Thermophysical properties of deep ocean sediments, Mar. Geotech., in press, 1983.

Hamann, S. D., Physico-Chemical Effects of Pressure, Butterworths Scientiflc, London, 1957.

Horai, K., Thermal conductivity of rock-forming minerals, J. Geophys. Res., 76, 1278-1308. 1971.

Horne, R. A., Structure makers and breakers in water: Pressure-induced changes in the hydration atmospheres of ions in solution, Arthur D. Little Inc. Tech. Rep. 3, Office of Nav. Res., Washington, D. C., 1964.

Horne, R. A., The physical chemistry and structure of sea water, Water Resour. Res., 1, 263-276, 1965.

Jaeger, J. C., The measurement of thermal conductivity and diffusivity with cylindrical probes, Eos Trans. AGU, 13, 708-710, 1958.

Keenan, J. H., F. G. Keyes, P. G. Hill, and J. G. Moore, Steam Tables: Thermodynamic Properties of Water including Vapor, Liquid, and Solid Phases, John wiley, New York, 1978.

Khitarov, N. I., and V. A. Pugin, Behavior of montmorillonite under elevated temperatures and pressures, Geochem. Int. , 3, 621-626, 1966.

Lang, w. J., The influence of pressure on the electrical resistivity of clay-water systems, Proc. Conf. Clays Clay Miner., 15th 455-468, 1967.

Langseth, M. G., Towards a submarine hydrology, Nature, 286, 554-555, 1980 .

Langseth, $\overline{M . G} .$, and B. M. Herman, Heat transfer in the oceanic crust of the Brazil Basin, J. Geophys. Res., 86, 10805-10819, 1981.

Lawson, A. W., and A. J. Hughes, High pressure properties of water, in High Pressure Physics and Chemistry, chap. 4, edited by R. S. Bradley, Academic, New York, 1963.

Lawson, A. W., R. Lowell, and A. L. Jain, Thermal conductivity of water at high pressures, $J$. Chem. Phys., 30, 643-647, 1959.

Lawver, L. A., D. L. Williams, and R. P. Von Herzen, A major geothermal anomaly in the Gulf of California, Nature, 257, 23-28, 1975.

MacDonald, K., and G. Simmons, Temperature coefficient of the thermal conductivities of ocean sediments, Deep Sea Res., 19, 669-671, 1972.

Mitchell, J. K., Fundamentals of Soil Behavior, John Wiley, New York, 1976. 
Müller, G., Diagenesis in argillaceous sediments, in Developments in Sedimentology, vol. 8 , Diagenesis in Sediments, chap. 4, edited by $G$. Larsen and G. V. Chilingar, Elsevier, New York, 1967.

Nickerson, C. R., Consolidation and permeabillty characteristics of deep-sea sediments: North central Pacific Ocean, M. S. thes1s, Worcester Polytech. Inst., Worcester, Mass., 1978.

Owen, B. B. and S. R. Brinkley, The effect of pressure upon the dielectric constants of liquids, Phys. Rev., 64, 32-36, 1943.

Ratcliffe, E. H., The thermal conductivities of ocean sediments, J. Geophys. Res., 65, 1535$1541,1960$.

Seyfried, W. E., and E. C. Thornton, Experimental and theoretical modeling of hydrothermal processes in the near field environment, Subseabed D1sposal Annual Report, Sandia Nat. Lab., Albuquerque, N.M., Jan.-Dec. 1981.

Silva, A. J.. J. R. Hetherman, and D. I. Calnan, Low-gradient permeability testing of finegrained marine sediments, ASTM Spec. Tech. Publ., STP 746, 121-136, 1981.

stern, 0., Zur Theorie der Elektrolytischen Doppelschlicht, z. Elektrochem., 30, 508-516, 1924.

van Olphen, H., An Introduction to Clay Colloid Chemistry, John Wiley, New York, 1977.
Verwey, E. J. W., and J. T. G. Overbeek, Theory of the Stability of Lyophobic Colloids, Elsevier, New York, 1948.

Von Herzen, R. P., and A. E. Maxwell, The measurement of thermal conductivity of deep-sea sediments by a needle-probe method, J. Geophys. Res., 64, 1557-1563, 1959.

Weaver, C. E., Geothermal alteration of clay minerals and shales: Diagenesis, Tech. Rep. ONWI-21, Office of Nucl. Waste Isolation, Battelle, Columbus, Ohio, 1979.

Williams, D.L., R. P. Von Herzen, J. G. Sclater, and R. N. Anderson, Lithospheric cooling on the Galapagos Spreading Center, Geophys. J. R. Astron. Soc., 38, 587-608, 1974 .

zisman, W. A., The effect of pressure on the electrical conductance of salt solutions in water, Phys. Rev., 39, 151-160, 1932.

R. Morin, Department of Earth and Planetary Sciences, Massachusetts Institute of Technology, Cambridge, MA 02139.

A. J. Silva, Department of Ocean Engineering, University of Rhode Island, Kingston, RI 02881 .

(Received July 12, 1982; revised April 25, 1983; accepted July 15, 1983.) 